Bryant University

Bryant Digital Repository

5-8-2019

\title{
Text versus pictures in advertising: effects of psychological distance and product type
}

Yung Kyun Choi

Dongguk University

Sukki Yoon

Bryant University, syoon@bryant.edu

Kacy Kim

Bryant University, kkim2@bryant.edu

Yeonshin Kim

Myongji University

Follow this and additional works at: https://digitalcommons.bryant.edu/mark_jou

Part of the Marketing Commons

\section{Recommended Citation}

Choi, Yung Kyun; Yoon, Sukki; Kim, Kacy; and Kim, Yeonshin, "Text versus pictures in advertising: effects of psychological distance and product type" (2019). Marketing Department Journal Articles. Paper 107.

https://digitalcommons.bryant.edu/mark_jou/107

This Article is brought to you for free and open access by the Marketing Faculty Publications and Research at Bryant Digital Repository. It has been accepted for inclusion in Marketing Department Journal Articles by an authorized administrator of Bryant Digital Repository. For more information, please contact dcommons@bryant.edu. 
Text versus Pictures in Advertising: Effects of Psychological Distance and Product Type

\begin{abstract}
The authors examine effects of marketing messages that use text or pictures for advertising durable or nondurable products appealing to consumers' perceptions of close versus far psychological distance. In three studies, ads featuring text (pictures) evoke more favorable attitudes and purchase intentions toward products to be purchased in the distant (close) future or at a distant (close) location. In addition, ads featuring text (pictures) evoke more favorable attitudes and purchase intentions for durable (nondurable) goods. The research shows that marketers will be most persuasive if they ensure congruence among message formats, product types, and psychological distance.
\end{abstract}


Text versus Pictures in Advertising: Effects of Psychological Distance and Product Type

Imagine that you are moving to a new apartment next week and need new furniture. Flipping through a magazine, you are drawn to an ad for a furniture store featuring pictures of tables, sofas, and chests-of-drawers. At the bottom of the ad appears basic information: phone number, website, and a nearby store location. Now imagine that instead of pictures, the ad features plain text listing "table, sofa, and drawers." Further imagine an alternative scenario. Instead of moving next week to a nearby apartment, you are moving next year to a faraway city. Under the two conditions-moving next week to a nearby location or moving next year to a faraway location - are you more attracted to pictures or descriptive text? Imagine another scenario: you encounter an ad for a hardware or fruit store. Would the pictorial or the textual ad be more appealing?

The questions are theoretically important. Consumers may respond differently to visual and verbal advertising messages (e.g., Amit et al. 2009; Rim et al. 2015) and to messages involving near or far psychological distance (e.g., Choi et al. 2017; Choi et al. 2019; Lee et al. 2019; Oh et al. 2019; Yoon et al. 2019). Indeed, social media communicators are more likely to share pictorial ads for events occurring in the near future, but they tend to share verbal ads for events occurring in the distant future (Choi et al. 2017). Advertising practitioners are particularly aware that they must strategically design message formats that are optimal for reaching target consumers, but few researchers have examined how message format and psychological distance influence advertising effectiveness. This research aims to fill this gap.

Responding to theoretical and practical demands to examine marketing message 
formats for congruency effects (e.g., McKay-Nesbitt and Yoon 2015), we empirically tested visual versus verbal formats to determine how they appeal to variations of psychological distance. We also tested whether durable and nondurable goods suggest varying distance perceptions that induce purchase likelihood.

We conducted three experimental studies to examine whether advertising is more effective if message formats are congruent with psychological distance. We expected that durable goods such as furniture tend to have long purchase cycles and thus evoke abstract mindsets and psychological distance. In contrast, nondurable goods such as fruit tend to have short purchase cycles, evoking concrete mindsets and psychological proximity.

In Studies 1A and 1B, we show that text is preferable for advertising products that will be consumed in a distant future or when stores are geographically distant. Extending the logic, in Study 2, we demonstrate that text is more effective for advertising durable goods, but pictures are better for advertising nondurable goods.

\section{PSYCHOLOGICAL DISTANCE AND CONGRUENCY EFFECTS}

Psychological distance is the subjective feeling that time, space, social distance, and probability are either close and immediate or distant and far away (Trope and Liberman 2010). Construal level theory (CLT) explains that people use abstract high-level construals for comprehending far psychological distance; they use low-level, concrete construals for comprehending close psychological distance. Levels increase as psychological distance recedes.

Messages are most persuasive when they evoke construal levels that are congruent 
with message recipients' psychological distance (e.g., Choi et al. 2019; Jin and He 2012; Lee et al. 2019; Martin et al. 2009; Rim et al. 2015). To arouse the most positive attitudes and purchase intentions, loss-framed messages should be matched with low-level construal, and gain-framed messages should be matched with high-level construal (Baek and Yoon 2017; Chang et al. 2015). Message elements must also be congruent with purchase time frames; for example, consumers planning to make purchases in the distant future will be drawn to fullsatisfaction guarantees, while consumers making immediate purchases will be drawn to attribute-specific guarantees (Jin and He 2012). Similarly, benefit-based appeals evoking high-construal levels will be more persuasive for temporally distant purchases, but attributebased appeals evoking low-construal levels will be more persuasive for temporally close purchases (Hernandez et al. 2015).

Regarding spatial distance, the most persuasive rational appeals feature close-up advertising images evoking low-level construals; the most persuasive emotional appeals feature long-shot advertising images evoking high-level construals (Kim et al. 2017). In a travel context, abstract messages are more persuasive for consumers planning to take vacations at distant times and locations, whereas concrete messages are more persuasive for those planning nearby, imminent vacations (Kim et al. 2016).

\section{MESSAGE FORMAT: PICTORIAL VERSUS TEXTUAL MESSAGES}

Pictures illustrate referent objects, conjure concrete perceptions, and impart a sense of closeness and proximity. In contrast, words convey the abstract essence of referent objects. According to the congruency principle, pictures should be congruent with close psychological distance, but words should be congruent with far psychological distance (Amit et al. 2009; 
Rim et al. 2015; Trope et al. 2007).

The word-proximity/picture-distance connection indicates that when individuals communicate with temporally, socially, or geographically close others, they prefer to use pictures evoking concrete thinking, but when they communicate with distant others, they prefer words evoking abstract thinking (Amit et al. 2013; Rim et al. 2015). Similarly, social media communications tend to use pictures for sending information about events perceived to be temporally close but tend to use text to send information about events perceived to be temporally distant (Choi et al. 2017). Accordingly, pictures tend to cause message recipients to think concretely and to perceive that a brand has high quality (Meyvis et al. 2012). Thus, pictures may be more persuasive for proximal consumption events, but words may be more persuasive for distal consumption events. Those observations motivated us to hypothesize:

H1: Under high (low) psychological distance conditions, textual (pictorial) ads will evoke more favorable brand attitudes and purchase intentions.

\section{PURCHASE FREQUENCY: DURABLE AND NONDURABLE GOODS}

Products have been classified into five groups according to nine criteria related to time and effort, frequency of purchase, and rapidity of consumption (Miracle 1965). For our purposes, we focus on Groups 1 and 4. Group 1 includes tangible, nondurable, convenience goods such as food, medicine, and fuel, sometimes called consumables, purchased and consumed frequently and rapidly, often in one use. Group 4 includes long-lasting durable goods such as furniture, automobiles, and machinery, purchased and consumed slowly and less frequently, while carrying higher risk in that outcomes may be uncertain for some time 
after purchase (Arens 1999; Richins and Bloch 1986; Seo et al. 2016).

How do consumers vary their buying behavior when purchasing nondurable or durable goods? When they buy nondurable, perishable goods such as fruit, they focus on concrete consumption details. For example, when they buy a bag of apples, they will consider where, when, and how they will consume the apples in the foreseeable future (e.g., "These apples will be a good snack when I go hiking with my friends this weekend"). However, when they buy durable long-lasting goods such as tools, they focus on more abstract considerations. For example, when they purchase a saw, they are likely to consider long-term usefulness (e.g., "This saw will be handy for gardening and house repairs").

In sum, CLT explains that temporal frames and temporal distance have similar effects. Events presented in a temporal day frame rather than a year frame appear more imminent, concrete, and threatening (Chandran and Menon 2004). Low (high) frequency music matched with abstract (concrete) representations and marketing messages evoke far (near) psychological distance (Sunaga 2018). Those findings are relevant to our focus on product purchase frequency and consumption pace. That is, consumers may perceive that products purchased frequently and consumed rapidly are relatively close and concrete; products purchased infrequently and consumed slowly appear relatively distant and abstract.

Individuals often experience causal uncertainty about interpreting actions, events, or objects in the social world; consequently, they tend to rely on abstract features for drawing broader meanings (Helzer and Edwards 2012). CLT explains that individuals tend to focus on abstract (concrete) and core (superficial) features for viewing products of low (high) purchase frequency and slow (rapid) consumption (Trope and Liberman 2003). Therefore, we expect that nondurable goods will evoke perceptions of closer psychological distance because 
outcomes are more certain and purchase cycles are more frequent. Thus, we hypothesize:

H2: For durable products, textual rather than pictorial ads will evoke more favorable brand attitudes and purchase intentions; for nondurable products, pictorial ads rather than textual ads will evoke more favorable brand attitudes and purchase intentions

To test our hypotheses, we conducted three studies.

\section{STUDY 1A}

Study 1 A was a 2 (temporal distance: close vs. distant) x 2 (message type: text vs. picture) between-subjects design for testing $\mathrm{H} 1$ predicating that high (low) psychological distance conditions will cause textual (pictorial) ads to induce more favorable brand attitudes and purchase intentions. Specifically, we predicted that text (pictures) would be more persuasive if the product would be consumed in the distant (near) future.

\section{Participants}

We recruited 110 undergraduate students from a private university in Seoul, in exchange for extra credit. Participants averaged 22 years-old $(\mathrm{SD}=2.70) ; 59$ percent were men.

\section{Stimuli, Procedure, and Measures}

We developed an advertisement for a fictitious furniture retailer in both text and picture formats (figure 1). To minimize confounds between conditions, the text and picture were similar in line and color. Against a white background, the text read: chest-of-drawers, chair, and table. The picture ad featured drawings of the furniture pieces. The brand logo, 
phone number, and web address appeared at the bottom of the ad.

$* * *$ Figure 1 about here***

In a pre-test, participants rated the pictorial versus textual message formats for concreteness on a seven-point scale. They perceived the pictorial advertisement to be more concrete $(\mathrm{M}=4.45$ vs $3.57 ; t(32)=-2.66, p<0.05)$ and imagery provoking $(\mathrm{M}=3.97 \mathrm{vs}$ 3.12; $t(32)=-2.05, p<0.05)$ than the textual advertisement (Jin and He, 2013; Martin et al., 2009). Hence, we confirmed previous studies (Amit et al., 2013; Meyvis et al., 2012): in comparison with text messages, pictorial messages appeared to be more concrete, inducing low-level construal.

We collected data at a computer lab. Participants sat at isolated computer monitors. To manipulate temporal distance, we asked participants to read scenarios about moving into a new apartment next week (a proximal event) or moving into a new apartment next year (a distal event). We randomly assigned them to one of the four experimental conditions. After they viewed the stimuli, they answered questions for the dependent measures.

Attitude toward the brand was measured on seven-point bipolar scales (dislike/like, bad/good, unfavorable/favorable, low quality/ high quality, unpleasant/ pleasant: $\alpha=.86$ ) (Bower and Landreth 2001; Martin et al. 2009). Purchase intentions were also measured on bipolar scales (unwilling/willing, would not/would, unlikely/likely, improbable/probable: $\alpha$ $=.97)(\mathrm{Li}$ et al. 2002; Verhagen and Dolen 2009).

\section{Results}

We submitted the attitude toward the brand measure to a 2 (temporal distance: close vs. distant) x 2 (message type: text vs. picture) factorial ANOVA. The analysis revealed no 
significant main effect of message type $\left(\mathrm{M}_{\text {picture }}=3.82, \mathrm{M}_{\text {text }}=4.07, F(1,106)=2.84, p\right.$ $=.10)$ or temporal distance $\left(\mathrm{M}_{\text {near }}=3.83, \mathrm{M}_{\text {distant }}=4.12, F(1,106)=2.16, p=.15\right)$.

Regarding our hypotheses, message type significantly interacted with temporal distance $(F(1$, $106)=5.17, p<.05)$. As predicted, participants had more favorable views toward products for distant future use depicted in text rather than picture $(\mathrm{M}=4.41(\mathrm{SD}=.17)$ vs. $3.74(.19)$, $F(1,106)=7.16, p<.01)$. However, textual or pictorial messages regarding products for near future use evoked no significant differences in brand attitude (3.78 (.15) vs. $3.88(.17), F(1$, $106)=.19, p=.66$ ) (Figure 2a), partially supporting H1 regarding attitudes toward ads.

Similarly, we submitted the purchase intention measure to a 2 (temporal distance: close vs. distant) x 2 (message type: text vs. picture) factorial ANOVA. The analysis revealed a significant main effect of message type $\left(\mathrm{M}_{\text {picture }}=3.16, \mathrm{M}_{\text {text }}=3.72 ; F(1,106)=4.71, p\right.$ $<.05)$ but no main effect of temporal distance $\left(\mathrm{M}_{\text {near }}=3.32, \mathrm{M}_{\text {distant }}=3.65, F(1,106)=.78, p\right.$ $=.38)$. Message type significantly interacted with temporal distance $(F(1,106)=5.89, p$ $<.05)$. As predicted, text rather than pictures evoked higher purchase intentions regarding products for distant future use $(4.23(.28)$ vs. $2.92(.32), F(1,106)=9.66, p<.005)$. However, text or pictures evoked no differences in purchase intentions regarding products for near future use $(3.29(.26)$ vs. $3.36(.28), F(1,106)=.04, p=.85$; figure $2 b)$, partially supporting H1 regarding purchase intentions.

\footnotetext{
***Figure 2 about here***
}

\section{Discussion}

In Study 1A, we tested pictures versus text for their advertising effectiveness according to temporal distance. We demonstrated that ad effectiveness depends on whether consumption occurs sooner or later. Consistent with H1, when consumers consider 
purchasing a product for distant future use, they will form more favorable attitudes and purchase intentions when products are advertised through text rather than pictures.

However, the data failed to support the second part of $\mathrm{H} 1$ in which we predicted that pictures would evoke more favorable attitudes and purchase intentions toward imminent product purchases, aligned with the CLT literature showing asymmetrical effects (e.g., Fujita 2008; Lee et al. 2014; Trope and Liberman 2000). We speculate that participants may have failed to perceive an event occurring in the following week as being a close event, and thus the floor effect might have prevailed.

\section{STUDY 1B}

In Study 1B, we tested H1 with another dimension of psychological distance: spatial distance. We predicted that text would be more effective when the seller was in a geographically close location, but pictures would be more effective when the seller was in a geographically far location (H1).

\section{Participants}

We recruited 75 undergraduate students from a private university in Seoul, in exchange for extra credit. Participants averaged 22 years-old $(\mathrm{SD}=1.96) ; 58.7$ percent were men.

\section{Stimulus and Procedure}

As in study 1A, we used text-based and picture-based ads for furniture. Rather than manipulate temporal distance, we manipulated spatial distance by altering store locations. At the bottom of each ad, we listed the seller's address as either geographically close to the 
students' location in Seoul or far away in Pusan; $456 \mathrm{~km}$ away. We used the scales from Study 1 A for brand attitude $(\alpha=.86)$ and purchase intentions $(\alpha=.96)$.

\section{Results}

We submitted the attitude toward the brand measure to a 2 (spatial distance: close vs. distant) x 2 (message type: text vs. picture) factorial ANOVA. The analysis revealed no significant main effect of message type $\left(\mathrm{M}_{\text {picture }}=3.99, \mathrm{M}_{\text {text }}=4.27, F(1,71)=1.93, p=.17\right)$ or spatial distance $\left(\mathrm{M}_{\text {near }}=4.18, \mathrm{M}_{\text {distant }}=4.07, F(1,71)=.20, p=.66\right)$. Regarding our hypothesis, message type significantly interacted with spatial distance $(F(1,71)=10.05, p$ $<.005)$. As predicted, text rather than pictures evoked more favorable attitudes toward the distant furniture store ad $(\mathrm{M}=4.50(\mathrm{SD}=.18)$ vs. $3.66(.18), F(1,71)=10.90, p<.005)$. However, text and pictures evoked the same brand attitudes for the close location (4.00 (.20) vs. $4.33(.18), F(1,71)=1.51, p=.22$; figure 3a). As in Study 1A, only the first part of $\mathrm{H} 1$ was supported.

Similarly, we submitted the purchase intention measure to a 2 (temporal distance: close vs. distant) x 2 (message type: text vs. picture) factorial ANOVA. The analysis revealed no significant main effect of message type $\left(\mathrm{M}_{\text {picture }}=2.91, \mathrm{M}_{\text {text }}=3.45, F(1,71)=2.70, p\right.$ $=.11)$ or spatial distance $\left(\mathrm{M}_{\text {near }}=3.18, \mathrm{M}_{\text {distant }}=3.15, F(1,71)=.00, p=.99\right)$. Regarding our hypothesis, message type significantly interacted with temporal distance $(F(1,74)=6.33, p$ $<.05)$. As predicted, text evoked higher intentions to purchase the product depicted at a distant furniture store $(3.80(.30)$ vs. $2.52(.30), F(1,71)=9.06, p<.005)$. However, text and pictures evoked the same purchase intentions regarding a close location (3.03 (.33) vs. 3.30 $(.30), F(1,71)=.37, p=.55$; figure $3 \mathrm{~b})$. As in Study $1 \mathrm{~A}$, only the first part of H1 was supported. 
$* * *$ Figure 3 about here***

\section{Discussion}

In Study 1B, we tested advertising effectiveness for visual versus verbal messages with different spatial distance. The results replicated the congruency effect from Study 1A. When participants considered purchasing furniture at a distant location, text evoked more favorable brand attitudes and purchase intentions.

However, as in Study 1A, the close location condition failed to show the predicted reverse effect. Although the mean differences were in the predicted direction, the nonsignificant results suggested a weak effect: that is, when participants contemplated purchasing from a nearby location, pictures versus text did not affect brand attitudes or purchase intentions. As in Study 1A, we speculate that participants might have perceived the store depicted in our scenario to be farther away than we intended, so a floor effect prevented the result from emerging.

\section{STUDY 2}

In Study 2, we tested H2 in which we predicted that text would be more effective for advertising durable goods, but pictures would be more effective for advertising nondurable goods.

\section{Participants}

We recruited 140 undergraduate students from a private university in the northeastern United States, in exchange for extra credit. Participants averaged 20 years-old $(\mathrm{SD}=1.37)$; 51.4 percent were women. 


\section{Stimuli and Procedure}

In addition to the furniture ad from Studies 1A and 1B, we created two fictitious print ads for new product categories: an ad for a fruit store (nondurables with high purchase frequency) and an ad for a hardware store (durables with low purchase frequency). The fruit store ad featured either text or images of apples, grapes, and strawberries; the hardware store ad featured either text or images of a hammer, screwdriver, and saw (figure 4).

$$
* * * \text { Figure } 4 \text { about here } * * *
$$

In a pretest $(n=63)$ participants indicated their average per-year frequency of purchasing these products $(1=0,2=1$ to 5 times, $3=6$ to 10 times, $4=11$ to 15 times, $5=$ more than 16 times). The results confirmed that fruit is frequently purchased: $52.4 \%$ indicated purchasing fruit more than 16 times per year. More rarely purchased $\left(\chi^{2}(8)=57.56\right.$, $\mathrm{p}<.001)$ are furniture $(100 \%$ indicated 0 to 5 purchases per year) and tools $(95.2 \%$ indicated purchasing tools 0 to 5 times per year).

We added the two product categories to replicate our findings from Studies 1A and $1 \mathrm{~B}$ with different durable goods, and to test the reversal effect specified in $\mathrm{H} 2$ with nondurable goods. Except for the variation in products, the stimulus ads and procedure were similar to those used in Studies 1A and B. We used the same scales for brand attitudes $(\alpha$ $=.97)$ and purchase intentions $(\alpha=.96)$.

As confounding checks, we measured several potential confounding variables between durable and nondurable products: product involvement, hedonic/utilitarian perceptions, product familiarity, and product knowledge. We found nonsignificant differences for product involvement (not at all important/very important: $\mathrm{M}_{\text {fruit }}=3.53, \mathrm{M}_{\text {furniture }}=3.28$, 
$\mathrm{M}_{\text {tool }}=3.60, F(2,137)=.41, p=.66$; not at all relevant/very relevant: $\mathrm{M}_{\text {fruit }}=3.78, \mathrm{M}_{\text {furniture }}=$ $\left.3.32, \mathrm{M}_{\text {tool }}=3.63, F(2,137)=.71, p=.49\right)$, hedonic/utilitarian perceptions (not at all hedonic/very hedonic: $\mathrm{M}_{\text {fruit }}=3.47, \mathrm{M}_{\text {furniture }}=3.47, \mathrm{M}_{\text {tool }}=3.50, F(2,137)=.01, p=.99$; not at all utilitarian/very utilitarian: $\mathrm{M}_{\text {fruit }}=3.38, \mathrm{M}_{\text {furniture }}=3.64, \mathrm{M}_{\text {tool }}=4.04, F(2,137)=$ $2.00, p=.14$ ), product familiarity (not familiar at all/very familiar: $\mathrm{M}_{\text {fruit }}=4.00, \mathrm{M}_{\text {furniture }}=$ $\left.3.87, \mathrm{M}_{\text {tool }}=4.27, F(2,137)=.35, p=.71\right)$, and product knowledge (not know at all $/ \mathrm{know}$ very much: $\left.\mathrm{M}_{\text {fruit }}=3.76, \mathrm{M}_{\text {furniture }}=3.19, \mathrm{M}_{\text {tool }}=3.88, F(2,137)=1.46, p=.24\right)$.

Accordingly, these product characteristics did not confound our durability/nondurability manipulation.

Participants perceived the pictorial advertisement to be more image provoking $(\mathrm{M}=$ 2.67 vs $1.76 ; t(54)=2.38, p<0.05)$ and vivid $(\mathrm{M}=2.03$ vs $1.41 ; t(55)=2.27, p<0.05)$ than the textual advertisement (Martin et al. 2009; Unnava and Burnkrant 1991), indicating that the pictorial message was more concrete and induced lower-level mental construal. Overall, the results indicated that we successfully manipulated message concreteness.

\section{Results}

We submitted the brand attitude measure to a 3 (product type: fruit vs. furniture vs. tool) x 2 (message type: text vs. picture) factorial ANOVA. The analysis revealed a main effect of product type $\left(\mathrm{M}_{\text {fruit }}=3.50(\mathrm{SD}=1.28), \mathrm{M}_{\text {furniture }}=2.84(\mathrm{SD}=1.29), \mathrm{M}_{\text {tool }}=\right.$ $3.37(\mathrm{SD}=1.29) ; F(2,134)=4.00, p<.05)$ but no main effect of message type $\left(\mathrm{M}_{\text {picture }}=3.15\right.$, $\left.\mathrm{M}_{\text {text }}=3.33, F(1,134)=.57, p=.45\right)$. Regarding our hypothesis, message type significantly interacted with product type $(F(2,134)=13.38, p<.001)$. As predicted, text evoked more favorable attitudes toward the infrequently purchased durable furniture $(\mathrm{M}=3.26(\mathrm{SD}=.25)$ vs. $2.48(.24), F(1,134)=5.09, p<.05)$ and tools $(3.91(.25)$ vs. $2.91(.23), F(1,134)=8.41, p$ 
$<.005)$, but pictures evoked more favorable attitudes toward the frequently purchased nondurable fruit $(\mathrm{M}=4.18(\mathrm{SD}=.25)$ vs. $2.86(.25), F(1,134)=14.02, p<.001)$ (figure $5 \mathrm{a})$.

Similarly, we submitted the purchase intention measure to a $3 \times 2$ factorial ANOVA and found no main effect of product type $\left(\mathrm{M}_{\text {fruit }}=3.15, \mathrm{M}_{\text {furniture }}=2.59, \mathrm{M}_{\text {tool }}=2.82 ; F(2\right.$, $134)=1.68, p=.19)$ or message type $\left(\mathrm{M}_{\text {picture }}=3.15, \mathrm{M}_{\text {text }}=3.33, F(1,134)=2.08, p=.15\right)$. Regarding our hypothesis, message type significantly interacted with product type $(F(2,134)$ $=9.33, p<.001)$. As predicted, text evoked higher purchase intentions for the infrequently purchased durable furniture $(3.07(.30)$ vs. $2.18(.28), F(1,134)=4.67, p<.05)$ and tools $(3.50(.30)$ vs. $2.25(.28), F(1,134)=9.42, p<.005)$, but pictures evoked higher purchase intentions for the frequently purchased nondurable fruit $(3.72(.30)$ vs. $2.61(.29), F(1,134)=$ $6.97, p<.01)$ (figure 5b).

\section{Covariance Analysis}

In testing H2, we assumed that furniture, tools, and fruit are purchased more or less frequently. However, participants may have varying attitudes toward the products depending on product involvement, familiarity, and perceptions regarding hedonic/utilitarian uses. We ran a set of ANCOVAs controlling for those factors as covariates, but the overall results remained unchanged.

Specifically, we ran four ANCOVAs including the following covariates: 1) involvement, 2) hedonic/utilitarian perception, 3) product familiarity, and 4) product knowledge. With each covariate in all four analyses, the $3 \times 2$ interaction on brand attitude remained significant (all $p$ 's $<.01$ ). That is, text evoked more favorable brand attitudes toward furniture (all $p$ 's $<.05)$ and tools (all $p$ 's $<.05)$, but pictures evoked more favorable attitudes toward fruit (all $p$ 's $<.1$ ). 
$* * *$ Figure 5 about here***

\section{Discussion}

Study 2 extends Studies 1A and 1B by examining whether message type has CLT congruency with product type. The results support $\mathrm{H} 2$ in showing that text (picture) based ads evoke more favorable attitudes and purchase intentions for durable (nondurable) goods.

The data from Studies 1A and 1B support H1 only for distant conditions, but the data from Study 2 support $\mathrm{H} 2$ for both distal durables and proximal nondurables. Because durable goods have a slow purchase cycle, message recipients appear to use abstract high-level construal for a product they perceive as psychological distant. In contrast, nondurable goods have a frequent purchase cycle, so message recipients use concrete low-level construal for a product they perceive as psychologically close.

\section{GENERAL DISCUSSION}

We have offered new insights and a novel perspective into how message format, psychological distance, and product type impact advertising effectiveness. Specifically, we show that pictorial and textual advertising messages have different effects on brand attitudes and purchase intentions depending on whether consumers perceive proximal or distal consumption. We show that message formats should be congruent with psychological distance to be persuasive. That is, pictures are more appropriate for advertising proximal consumption; text is more appropriate for distal consumption. Furthermore, product essences determine whether consumers perceive products to be distant or close. Durable goods tend to 
trigger high-level construal, while nondurable goods trigger low-level construal. Accordingly, picture (text) based ads should be matched with nondurable (durable) goods to enhance brand attitudes and purchase intentions.

We add to the extant literature on CLT (e.g., Trope and Liberman 2000; 2003; 2010; Yoon et al. 2019) by integrating temporal and spatial distance, two common dimensions of psychological distance, to show their relation to the processing of pictorial and textual advertising. In a unique contribution, we use a CLT context to identify previously uninvestigated moderating variables — durable versus nondurable goods — evoking high or low construal. By showing that purchase cycles evoke temporal frames, we open new research paths regarding temporal distance in consumption contexts.

Second, we complement prior research by suggesting that pictures initiate bottom-up, clear, and concrete processing, but words initiate abstract top-down processing using previously gained knowledge. This idea is theoretically important: if product consumption is distal, consumers must make abstract brand-related decisions about future consumption. Time lags usually separate purchase decisions from actual consumption, so text might be more appropriate in pre-planned consumption situations. Our data align with that speculation: Studies $1 \mathrm{~A}$ and $1 \mathrm{~B}$ show that the picture-text effect was strongly pronounced for distal consumption but weaker for proximal consumption. The small sample in Study 1B could explain the nonsignificant results. A replication with a larger sample may clarify how close the consumption must be before pictures are more effective than text.

We suggest that marketers can use our findings as a guideline for designing advertising messages. First, we recommend that they should consider the purchase frequency and consumption cycle of products or services. Marketers of convenience products should 
provide concrete, visual information, but marketers of durable goods should focus on textual information to allow customers to abstractly process messages. Relatedly, infrequent customers of luxury goods have been shown to dismiss ads touting product quality and instead favor advertisements appealing to their desired self-concepts and high-level construal (Freitas et al. 2008). Likewise, we advise retail outlets that are located far away from consumers to use text-based promotional materials.

Several caveats must be mentioned. First, most real-world advertising contains both visual and verbal elements. Future research might observe how relative proportions of pictorial and textual elements within a single ad might affect construal levels, brand attitudes, and purchase intentions. In this sense, the CLT perspective might offer a new explanation regarding the need to match symbolic connotations conveyed by pictures and advertising slogans (Peracchio and Meyers-Levy 2005).

Next, although the Study 2 results remained unchanged after we controlled for product involvement, hedonic/utilitarian perceptions, familiarity, and knowledge, future research should still control for those factors by creating different experimental conditions for utilitarian and hedonic products (e.g., toilet paper vs. candy; McKay-Nesbitt, Ryan, and Yoon 2018).

Future research might also consider degrees of abstractness within texts and pictures. For example, some texts may fully describe product color and shape, while others might omit details and simply use product names. Similarly, realistic, full-color, detailed pictures may elicit lower construal levels than simple, black-and-white drawings. Indeed, abstract language used in positive word-of-mouth causes message recipients to infer that message senders have more favorable product attitudes and higher buying intentions for focal products (Schellekens 
et al. 2010). In a study of image proximity, close-up advertising images evoked low-level construals and higher evaluations of rational appeals, while long-shot images evoked highlevel construals and higher evaluations of emotional appeals (e.g., Kim et al. 2017).

At a broad conceptual level, our work may be considered a replication of previous research. For example, Amit, Wakslak, and Trope (2013) showed that people prefer using pictures (words) when communicating with proximal (distal) others. Rim et al. (2015) reported that pictures (words) cause people to think of events in terms of concrete (abstract) features. Those earlier findings highlighted how pictures and words have different effects on interpersonal communication and information processing styles. Although our findings align with earlier findings under the broad theoretical scope of construal level theory, we provide unique marketing insights into how visual and verbal message strategies impact consumer perceptions of advertising. 


\section{REFERENCES}

Amit, E., Algom, D., \& Trope, Y. (2009) Distance-dependent processing of pictures and words, Journal of Experimental Psychology: General, 138(3), pp. 400-415.

Amit, E., Wakslak, C., \& Trope, Y. (2013) The use of visual and verbal means of communication across psychological distance, Personality and Social Psychology Bulletin, 39(1), pp. 43-56.

Arens, W.F. (1999) Contemporary Advertising, Boston: Irwin/McGraw-Hill.

Baek, T. \& Yoon, S. (2017). Guilt and shame: Environmental message framing effects. Journal of Advertising, 46(3), 440-453.

Bower, A., \& Landreth, S. (2001) Is beauty best? Highly versus normally attractive models in advertising, Journal of Advertising, 30(1), pp. 1-12.

Chandran, S., \& Menon, G. (2004) When a day means more than a year: effects of temporal framing on judgments of health risk, Journal of Consumer Research, 31, pp. 375-389.

Chang, H., Zhang, L., \& Xie, G. (2015) Message framing in green advertising: the effects of construal level and consumer environmental concern, International Journal of Advertising, 34(1), pp. 158-176.

Choi, Y., Seo, Y., Wagner, U., \& Yoon. S. (in press). Matching Luxury Brand Appeals with Attitude Functions on Social Media across Cultures. Journal of Business Research.

Choi, Y., Seo, Y., \& Yoon, S. (2017) E-WOM messaging on social media: social ties, temporal distance, and message concreteness, Internet Research, 27(3), pp. 495-505.

Freitas, A., Langsam, K., Clark, S., \& Moeller, S. (2008) Seeing oneself in one's choices: 
construal level and self-pertinence of electoral and consumer decisions, Journal of Experimental Social Psychology, 44, pp. 1174-1179.

Fujita, Kentaro. (2008) Seeing the forest beyond the trees: A construal-level approach to selfcontrol, Social and Personality Psychology Compass, 2(3), 1475-1496.

Helzer, E., \& Edwards, J. (2012) Causal uncertainty prompts abstract construal of behavior, Social Cognition, 30(5). Pp. 519-536.

Hernandez, J., Wright, S., \& Rodrigues, F. (2015) Attributes versus benefits: the role of construal levels and appeal type on the persuasiveness of marketing messages, Journal of Advertising, 44(3), pp. 243-253.

Hughes A., Wilkens T., Wildemuth B.M., \& Marchionini G. (2003) Text or pictures? An eyetracking study of how people view digital video surrogates. In: Bakker E.M., Lew M.S., Huang T.S., Sebe N., Zhou X.S. (eds) Image and Video Retrieval. CIVR 2003. Lecture Notes in Computer Science, 2728. Springer, Berlin, Heidelberg, pp. 271-280.

Jin, L., \& He, Y. (2012) Designing service guarantees with construal fit: effects of temporal distance on consumer responses to service guarantees, Journal of Service Research, 16(2), pp. 202-215.

Kim, J., Kim, P., Kim, J., \& Magnini, V. (2016) Application of construal-level theory to promotional strategies in the hotel industry, Journal of Travel Research, 55(3), pp. 340-352. Kim, K., Lee, S., \& Choi, Y. (2017). Image proximity in advertising appeals: spatial distance and product types, Journal of Business Research (In press).

[https://doi.org/10.1016/j.jbusres.2017.08.031]. 
Lee, Hyojin, Xiaoyan Deng, H. Rao Unnava, \& Kentaro Fujita (2014) Monochrome Forests and Colorful Trees: The Effect of Black-and-White versus Color Imagery on Construal level, Journal of Consumer Research, 41(4), pp. 1015-1032.

Lee, Y., Yoon, S., Chun, S., Park, C., \& Kim, K. (2019). How liberals and conservatives respond to feasibility and desirability appeals in anti-tobacco campaigns. Asian Journal of Communication, 29(1), pp. 55-72.

Li, H., Daugherty, T., \& Biocca, F. (2002) Impact of 3-D advertising on product knowledge, brand attitude, and purchase intention: the mediating role of presence, Journal of Advertising, 31(3), pp. 43-57.

Martin, B., Gnoth, J., \& Strong, C. (2009) Temporal construal in advertising, Journal of Advertising, 38(3), pp. 5-19.

McKay-Nesbitt, J., Ryan, C., \& Yoon, S. (2018) College students' online purchase attitudes and intentions: gender, product type, and risk, International Journal of Electronic Marketing and Retailing, 9(3), pp. 207-229.

McKay-Nesbitt, J., \& Yoon, S. (2015) Social marketing communication messages: How congruence between source and content influences physical activity attitudes, Journal of Social Marketing, 5(1), pp. 40-55.

Meyvis, T., Goldsmith, K., \& Dhar, R. (2012) The importance of the context in brand extension: How pictures and comparisons shift consumers' focus from fit to quality, Journal of Marketing Research, 49(2), pp. 206-217.

Miracle, G.E. (1965) Product characteristics and marketing strategy, Journal of Marketing, 29(1), pp. 18-24. 
Oh, S., Yoon. S., \& Vargas. P. T. (2019). “In-depth” incidental exposure: How processing difficulty and processing style affect evaluations of transparent overlay images. European Journal of Marketing, 53(2), 279-298

Peracchio, L. \& Meyers-Levy, J. (2005) Using stylistic properties of ad pictures to communicate with consumers, Journal of Consumer Research, 32(1), pp. 29-40.

Richins, M., \& Bloch, P. (1986) After the new wears off: the temporal context of product involvement, Journal of Consumer Research, 13(2), pp. 280-285.

Rim, S., Amit, E., Fujita, K., Trope, Y., Halbeisen, G., \& Algom, D. (2015) How words transcend and pictures immerse: On the association between medium and level of construal, Social Psychological and Personality Science, 6(2), pp. 123-130.

Schellekens, G., Verlegh, P., \& Smidts, A. (2010) Language abstraction in word of mouth, Journal of Consumer Research, 37, 207-223.

Seo, J., Yoon, S., \& Vangelova, M. (2016). Shopping plans, buying motivations, and return policies: Impacts on product returns and purchase likelihood. Marketing Letters, 27(4), 645659.

Sunaga, T. (2018) How the sound frequency of background music influences consumers' perceptions and decision making, Psychology \& Marketing, 35, pp. 253-267.

Trope, Yaacov and Nira Liberman (2000) Temporal construal and time-dependent changes in preference, Journal of Personality and Social Psychology, 79(6), pp. 876-889.

Trope, Y., \& Liberman, N. (2003) Temporal construal, Psychological Review, 110(3), pp. 403-421. 
Trope, Y., \& Liberman, N. (2010) Construal-level theory of psychological distance, Psychological Review, 117(2), pp. 440-463.

Trope, Y., Liberman, N., \& Wakslak, C. (2007) Construal levels and psychological distance: effects on representation, prediction, evaluation, and behavior, Journal of Consumer Psychology, 17(2), 83-95.

Unnava, H.R. \& Burnkrant, R. (1991) An imagery-processing view of the role of pictures in print advertisements, Journal of Marketing Research, 28(2), pp. 226-231.

Verhagen, T. \& Dolen, W. (2009) Online purchase intentions: a multi-channel store image perspective, Information \& Management, 46(2), pp. 77-82.

Yoon, S., Kim, K., Beltis, A., Logan, J., \& Subramanian, G. (in press). Red Sox versus Yankees: Sports team rivalry, sports symbols, and distance performance. Journal of Global Sport Management. 


\section{FIGURES}

Figure 1. Stimulus ads for Study 1 (Picture vs. Word)

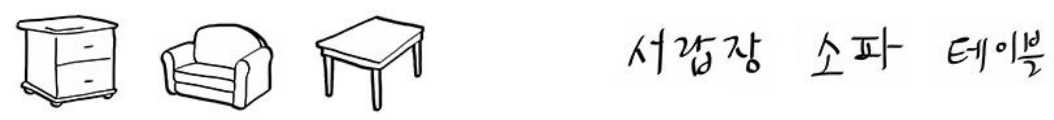

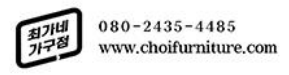

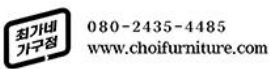


Figure 2. Interaction between message format and temporal distance
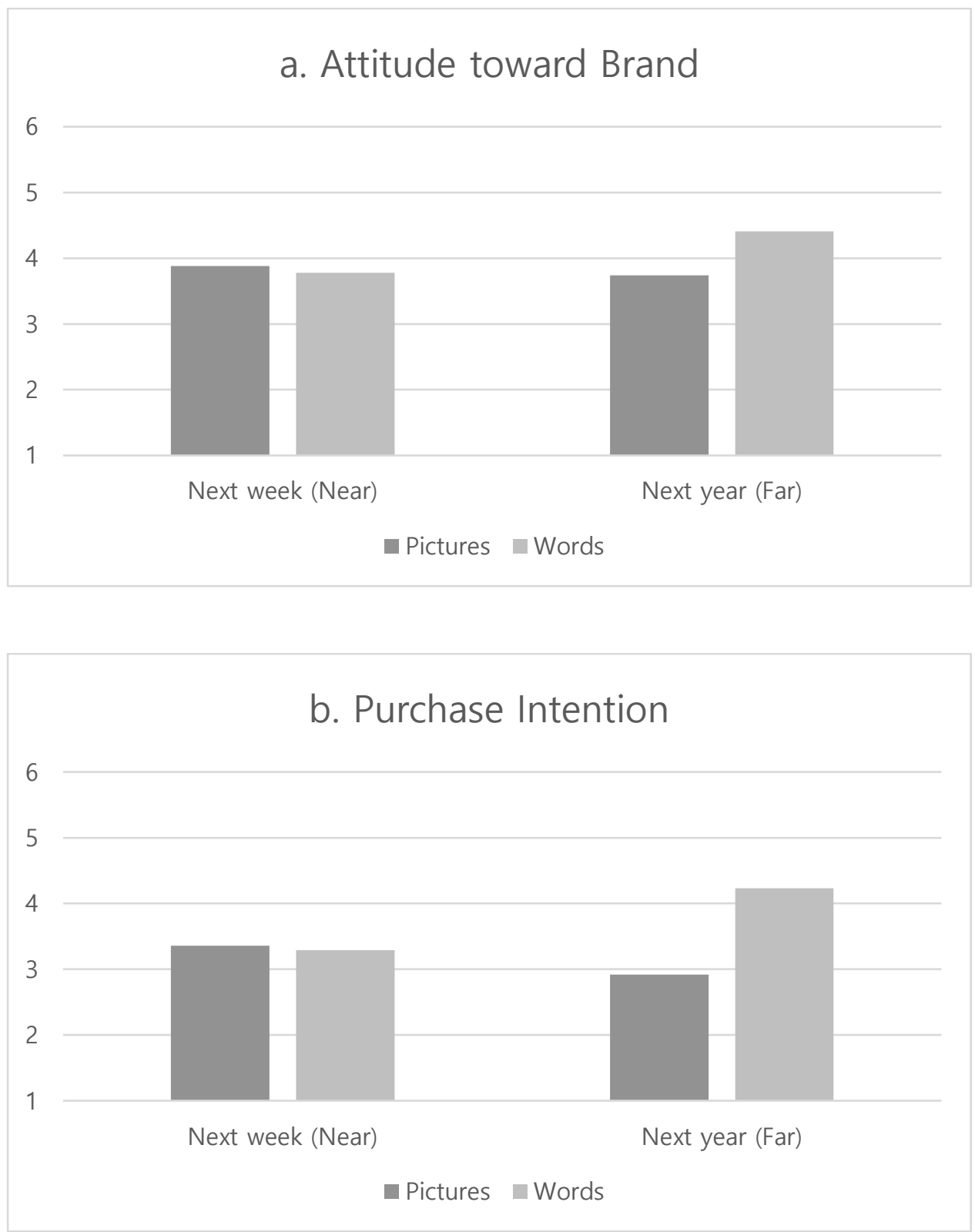
Figure 3. Interaction between message format and spatial distance
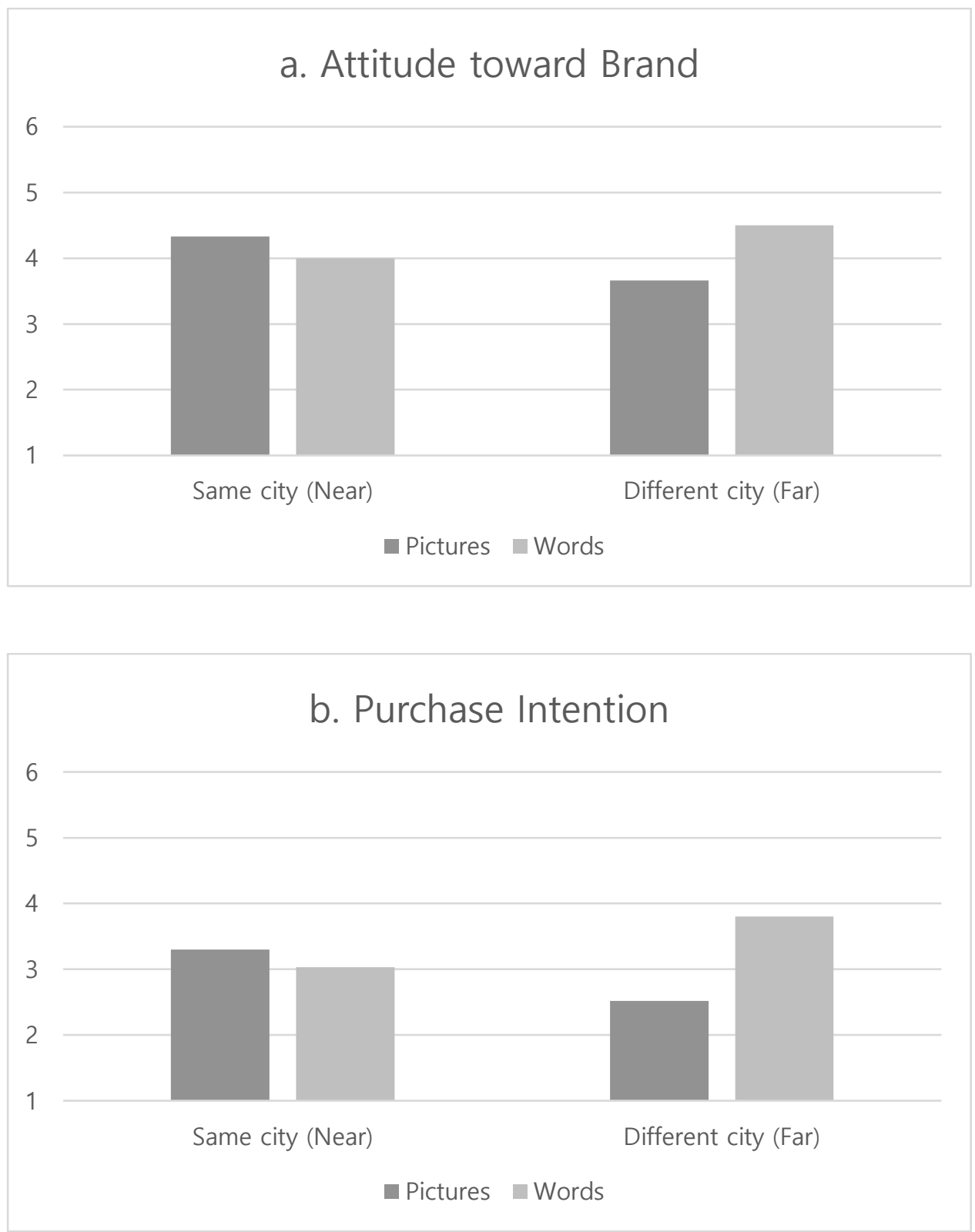
Figure 4. Stimulus ads for Study 2 (Picture vs. Word)

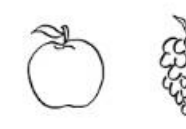

Apple Grape Strawberry

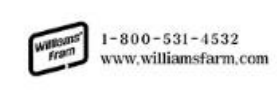

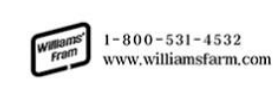

की

Hammer Screwdriver Saw

trimat

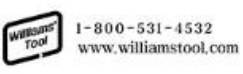


Figure 5. Interaction between message format and products' purchase frequency
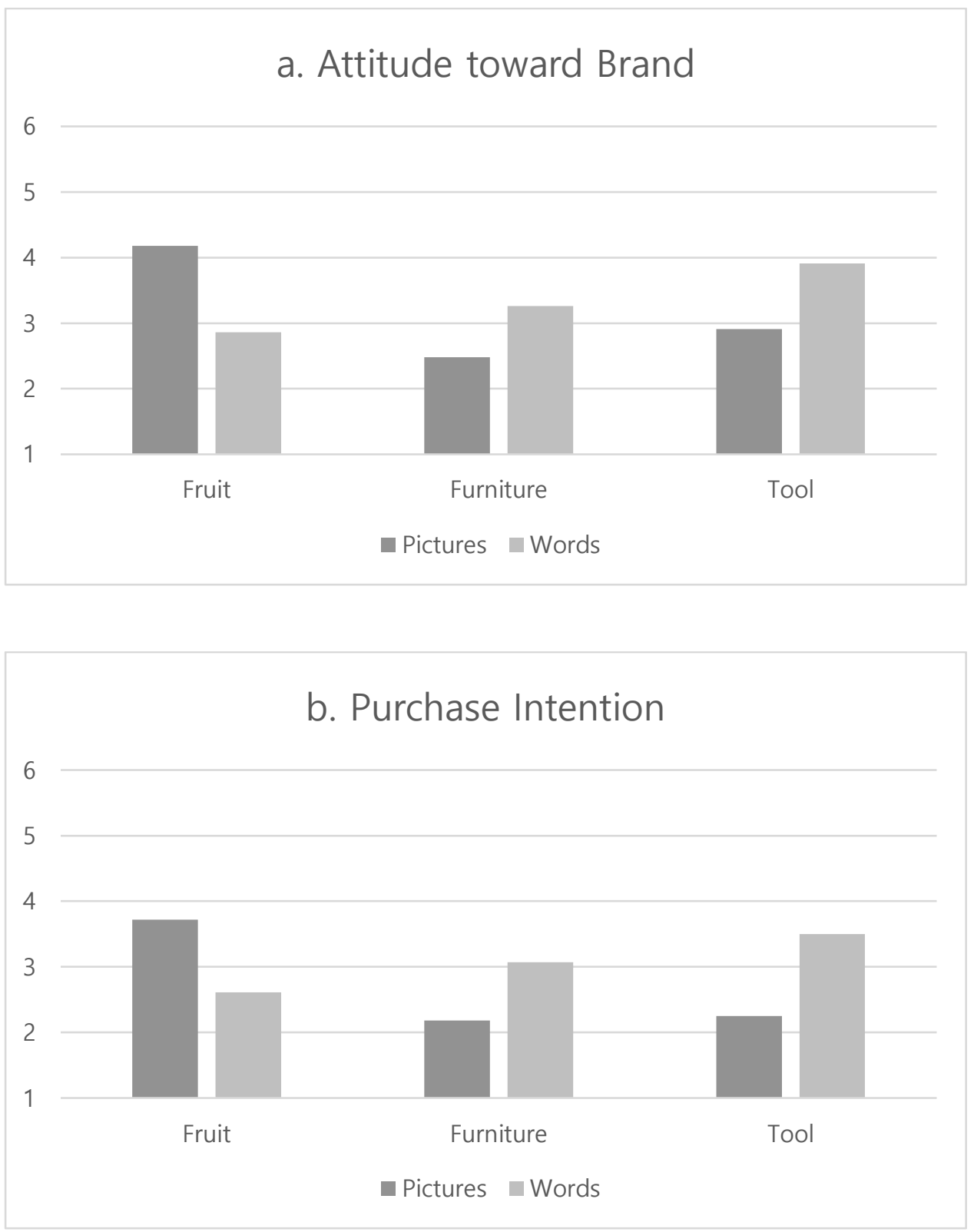